ORIGINAL ARTICLE

\title{
Asthma, chronic bronchitis, and exposure to irritant agents in occupational domestic cleaning: a nested case-control study
}

\author{
M Medina-Ramón, J P Zock, M Kogevinas, J Sunyer, Y Torralba, A Borrell, F Burgos, J M Antó
}

Occup Environ Med 2005;62:598-606. doi: 10.1136/oem.2004.017640

See end of article for authors' affiliations

Correspondence to: Dr J M Antó, Respiratory and Environmental Health Research Unit, Municipal Institute of Medical

Research (IMIM), Dr

Aiguader 80, E-08003

Barcelona, Spain;

jmanto@imim.es

Accepted

16 February 2005

\begin{abstract}
Background: Women employed in domestic cleaning are at increased risk for symptoms of obstructive lung disease, but the agents responsible are unknown.

Aims: To investigate common tasks and products in occupational domestic cleaning in relation to respiratory morbidity.

Methods: Case-control study in domestic cleaning women nested within a large population based survey of women aged 30-65 years; 160 domestic cleaning women with asthma symptoms, chronic bronchitis symptoms, or both and 386 without a history of respiratory symptoms were identified. Detailed exposures were evaluated for 40 cases who reported still having symptoms at the recruitment interview, and 155 controls who reported not having symptoms. All tasks performed and products used when cleaning houses were determined in a face-to-face interview. Lung function, methacholine challenge, and serum IgE testing were performed. Personal exposure measurements of airborne chlorine and ammonia were performed in a subsample. Associations between asthma, chronic bronchitis, and cleaning exposures were evaluated using multiple logistic regression analysis.

Results: Airborne chlorine (median level 0-0.4 ppm) and ammonia (0.6-6.4 ppm) were detectable during occupational domestic cleaning activities. Cases used bleach more frequently than controls; adjusted odds ratio (OR) for intermediate exposure was $3.3(95 \% \mathrm{Cl} 0.9$ to 11$)$ and for high exposure 4.9 (1.5 to 15). Other independent associations included accidental inhalation of vapours and gases from cleaning agents and washing dishes. These associations were more pronounced for cases with asthma symptoms than for those with symptoms of chronic bronchitis, but were not related to sensitisation to common allergens. Conclusions: Asthma symptoms in domestic cleaning women are associated with exposure to bleach and possibly other irritant agents. The public health impact of the use of irritant cleaning products could be widespread since the use of these products is common both in the workplace and at home.
\end{abstract}

\footnotetext{
C
} ommunity based studies have shown that cleaning workers have an increased risk for asthma and other respiratory symptoms, ${ }^{1-4}$ but the agents responsible remain unclear. Recent studies have shown a particularly high risk of respiratory morbidity in women employed in domestic cleaning. ${ }^{56}$ In a large cross-sectional study we previously showed that women employed in domestic cleaning had an excess risk of both asthma and chronic bronchitis. ${ }^{6}$ In this general population sample of women aged 30-65 years, the risk of asthma attributable to employment in domestic cleaning was about $25 \%$. To our knowledge, to date no study has been published evaluating specific risk factors for asthma or chronic bronchitis in domestic cleaning workers. This is a potentially important public health issue since domestic cleaning is one of the most common female occupations in many countries, and relevant exposures are shared by housewives and others cleaning their own homes. ${ }^{256}$ Here we report the results of a population based nested case-control study among women employed in domestic cleaning, aiming at identifying which agents in occupational domestic cleaning are related to asthma and chronic bronchitis.

\section{METHODS}

Study design and population

Between June 2000 and July 2001 a population based survey was conducted among 4521 women between 30 and 65 years of age living in Cornellà, a city in the metropolitan area of
Barcelona, Spain. ${ }^{6}$ Within this study population, a nested case-control study among domestic cleaning women was performed between June 2001 and April 2002. Because symptoms of asthma typically show variable patterns in time, ${ }^{7}$ case-control status was determined on the basis of the presence or absence of respiratory symptoms at the time of both studies. Cases were defined as women with asthma and/ or chronic bronchitis in both the population based survey and the case-control study. Asthma was defined as having had an attack of asthma and/or being woken by an attack of shortness of breath in the last 12 months, and chronic bronchitis was defined as having regular cough and/or regularly bringing up phlegm at least three months each year. Controls were defined as women who reported not having experienced respiratory symptoms in the preceding year and did not have a history of asthma at both the population based interview and the case-control interview.

From the population based survey 650 women currently employed in domestic cleaning work were identified, among whom 160 had asthma and/or chronic bronchitis symptoms, and 386 were without respiratory symptoms (fig 1). Both groups were contacted again, and those who were still

Abbreviations: BHR, bronchial hyperresponsiveness; COPD, chronic obstructive pulmonary disease; ECRHS, European Community Respiratory Health Survey; $\mathrm{FEV}_{1}$, forced respiratory volume in 1 second; FVC, forced vital capacity; RADS, reactive airways dysfunction syndrome 
employed in domestic cleaning in the study area were invited to participate in the case-control study. Eighty seven women who had reported asthma symptoms, chronic bronchitis symptoms, or both in the population based survey (response rate $74 \%$ ) and 194 women without respiratory symptoms $(69 \%)$ agreed to participate. There were no major differences in age (median $51 v 53$ years), smoking (15\% v 13\% current smokers), and educational level (46\% v 43\% at least primary education) between responders and non-responders. There were relatively more participant cases who were also employed in non-domestic cleaning compared to participant controls. Since change in symptom status between the population based survey and the case-control recruitment was common in both groups, we defined cases and controls according to the presence or absence of symptoms on both occasions, resulting in 40 cases and 155 controls. Participants provided written informed consent.

\section{Exposure assessment}

Detailed information about history of employment and characteristics of current domestic cleaning work was obtained during the case-control study. A questionnaire was developed based on a previous study in Spanish cleaners ${ }^{5}$ and on a job specific questionnaire used within the European Community Respiratory Health Survey (ECRHS), ${ }^{8}$ and revised after a pilot study. Subjects were asked about specific cleaning characteristics separately for each home where currently employed, and their own home. The frequency of performance of 23 different cleaning tasks and use of 22 different cleaning products at the time of the case-control interview was recorded as times per week, times per month, or times per year. All frequencies were converted into times per year and exposures in all homes, including their own, were summed to obtain a total frequency of exposure to each task and each product. Questions about accidents that

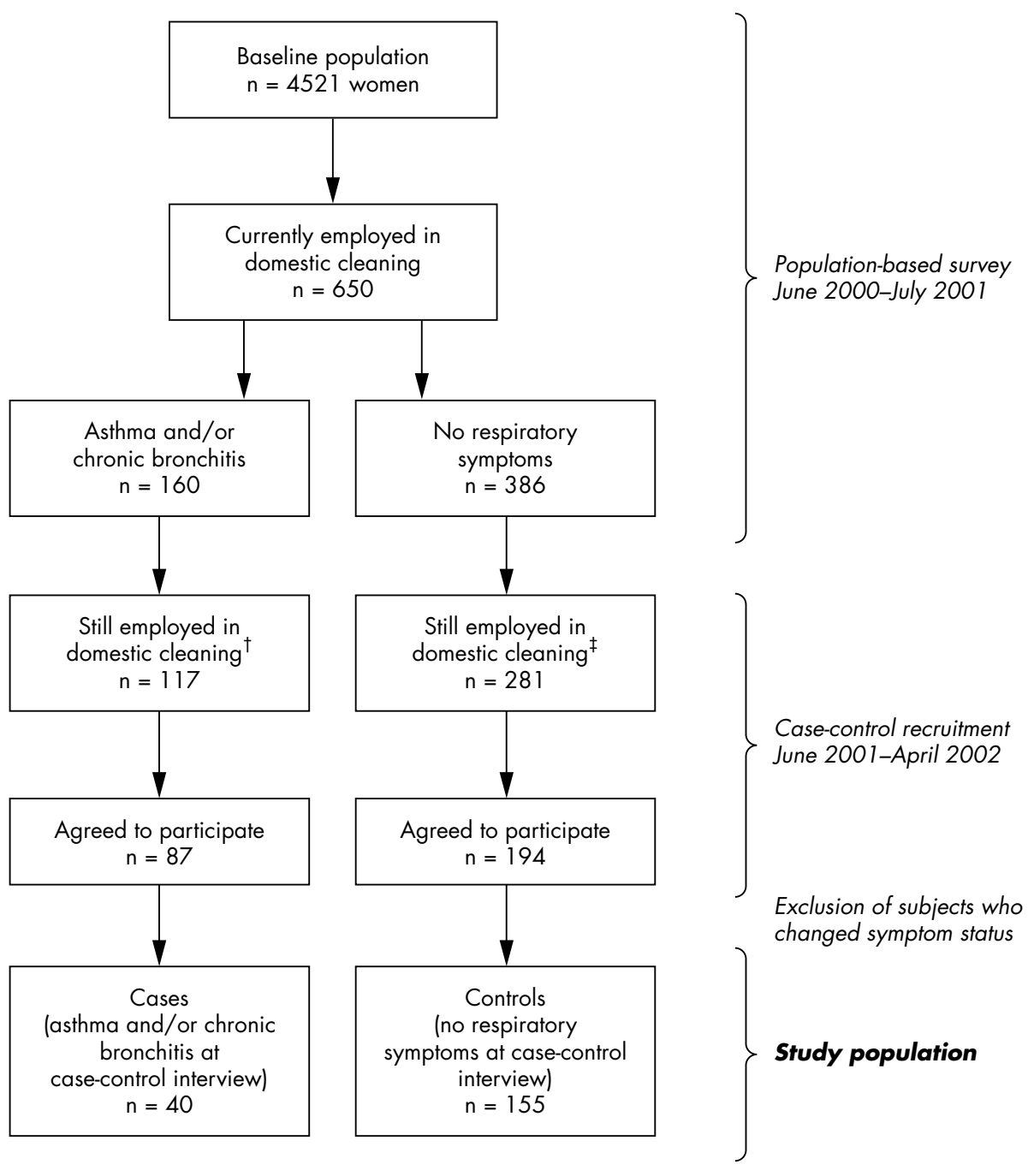

\footnotetext{
†38 women with symptoms had quit domestic cleaning employment and five had moved from the study area during the period elapsed between the population-based survey and the case-control recruitment

¥97 women without symptoms had quit domestic cleaning employment and eight had moved from the study area during the period elapsed between the population-based survey and the case-control recruitment
}

Figure 1 Selection of the population for a case-control study among women employed in domestic cleaning, nested within a population based survey (see Medina-Ramón et a ${ }^{k}$ ). 
occurred when using a single or mixture of several cleaning products leading to the inhalation of an important quantity of vapours, gas, or fumes were also included. Full occupational history was obtained, and exposure to asthma related agents in all jobs was assessed by means of a job-exposure matrix with additional expert judgement. ${ }^{9}$ The questionnaire was administered face-to-face by a trained research nurse, blind to case-control status. One case and 14 controls were interviewed by telephone.

Ad hoc short term personal exposure measurements of airborne chlorine and ammonia were performed in a subsample of 10 subjects (four cases and six controls) in the period February-May 2002. One measurement session per individual was performed during domestic cleaning work in one of the homes where the subject was employed. Chlorine and ammonia were measured at the same time with 5-second intervals using single sensor gas detectors in combination with data loggers (Biosystems, Middletown, $\mathrm{CT}$ ). The corresponding cleaning tasks and used products were recorded simultaneously. The purpose of this ad hoc study was to describe common exposures during domestic cleaning work, and not to compare exposure levels between cases and controls.

\section{Respiratory symptoms, lung function, and allergy testing}

The case-control interview included questions on a variety of respiratory symptoms and chronic conditions, medication use, and smoking habits obtained from the ECRHS questionnaire. ${ }^{10}$ Subjects performed at least three acceptable reproducible spirometric manoeuvres following standard spirometry procedures. ${ }^{11}$ Forced vital capacity (FVC) and forced expiratory volume in one second $\left(\mathrm{FEV}_{1}\right)$ were determined. Predicted values were obtained from Spanish reference equations. ${ }^{12}$ Chronic obstructive pulmonary disease (COPD) was defined as both a $\mathrm{FEV}_{1}$ less than $80 \%$ of its predicted value and a $\mathrm{FEV}_{1}$ to $\mathrm{FVC}$ ratio less than $0.7 .^{13}$ Methacholine challenge was carried out using a dosimeter (Mefar, Brescia, Italy) according to ECRHS methodology. ${ }^{14}$ Bronchial hyperresponsiveness (BHR) was defined as a fall of at least $20 \%$ in $\mathrm{FEV}_{1}$ associated with a methacholine dose of $1 \mathrm{mg}(8 \mu \mathrm{mol})$ or less. Methacholine challenge was not performed for safety reasons in women with a baseline $\mathrm{FEV}_{1}$ of either less than $1.5 \mathrm{l}$ or less than $70 \%$ of the predicted value. Total and specific serum immunoglobulin E (IgE) levels against nine common environmental aeroallergens (Dermatophagoides pteronyssinus, D farinae, cat, dog, Cladosporium herbarum, Timothy grass, Parietaria judaica, Alternaria alternate, and latex) were determined using the CAP system (Pharmacia Diagnostics, Uppsala, Sweden). Atopy was defined as a specific IgE level of greater than $0.35 \mathrm{kU} / \mathrm{l}$ for at least one of these nine allergens.

\section{Statistical analyses}

Considering the large number of cleaning exposure variables, the first analytical step consisted of a quantitative description of all obtained data on products and cleaning tasks. Correlations between continuous frequencies of cleaning tasks and cleaning products were evaluated using Spearman's correlation coefficient $\left(r_{s}\right)$. Associations between case-control status and potential risk factors were estimated by means of the odds ratio (OR) with 95\% confidence intervals (CI) using unconditional logistic regression analysis. Continuous frequencies of cleaning tasks and cleaning products were categorised by default into three exposure groups using tertiles as cut-off points, although variables with a distribution largely skewed to the right were dichotomised using arbitrarily a fixed cut-off point of 12 times per year. Unadjusted ORs for categorised frequencies of all cleaning tasks and cleaning products were calculated. A multivariate model was developed including cleaning tasks and products, current or former employment in nondomestic cleaning jobs, and a history of inhalation accidents related to cleaning products. Exposure variables that showed an unadjusted $\mathrm{p}$ value less than 0.1 in any of the categories were considered for multivariate modelling. Mutual associations between all exposure variables were evaluated to anticipate potential colinearity and confounding. Explanatory variables with a $\mathrm{p}$ value less than 0.1 were maintained in the final model. All steps in the multivariate modelling process were adjusted for age tertile and smoking status (never, current, and former). The final multivariate model was obtained for all cases, and subsequently also applied for asthma cases and for chronic bronchitis cases, using all controls as comparison group. All analyses were done using Stata version 7 (Stata Corporation, College Station, TX, USA).

The study protocol was approved by the Clinical Research Ethical Committee of the Municipal Institute of Health Care (CEIC-IMAS), created and accredited on 11 November 1993 by the General Management of Health Resources of the Generalitat de Catalunya, in accordance with an "Ordinance dated 26 October 1992".

\section{RESULTS}

The mean age of the study population was approximately 50 years, and similar for cases and controls (table 1). Current smoking was in general uncommon but more prevalent in cases than in controls. At the time of the case-control interview, 14 women reported current asthma symptoms only, 16 reported chronic bronchitis symptoms only, and 10 reported both types of symptoms. FEV 1 was very close to the predicted value for both cases and controls, but the prevalence of bronchial hyperresponsiveness was higher in cases than in controls. The prevalence of atopy was the same in cases and controls, although the mean total serum IgE level was higher in cases. Of the 24 cases with asthma symptoms, $16(67 \%)$ reported their first attack of asthma after starting working as a domestic cleaner. Among the 26 chronic bronchitis cases, 14 had chronic cough only, six had chronic phlegm only, and six reported both.

Total duration of employment in domestic cleaning and current number of working hours per week was comparable for cases and controls (table 1). The median number of homes where women were currently employed was two (range one to seven) in both cases and controls. Present or past employment in a non-domestic cleaning job was reported more frequently by cases than by controls (OR 6.4; 95\% CI 2.9 to 15), but employment in other jobs with asthma related exposures was similar (OR 0.7 ; 95\% CI 0.3 to 1.5 ). More than half of the study population reported having at some time accidentally inhaled an important quantity of vapours, gas, or fumes when using cleaning products. This had occurred more frequently in cases compared to controls (OR 3.3; 95\% CI 1.5 to 7.4). About two thirds of the reported accidents were related to the mixing of two or more cleaning products, principally mixtures with bleach. Accidents related to one single product predominantly involved hydrochloric acid or ammonia.

Most cleaning tasks were performed by the vast majority of the cleaning women, but the frequency of performance varied substantially between tasks (table 2). Some of the tasks such as cleaning the bathroom or sweeping were performed on average more than once a day, whereas other tasks such as cleaning the oven were normally performed once or twice a month. Most of the tasks were performed with a similar frequency by cases and controls; statistically significant associations were only found for intermediate frequency of 
Table 1 Demographic, respiratory health, and occupational characteristics of the study population

\begin{tabular}{|c|c|c|}
\hline & Cases & Controls \\
\hline $\begin{array}{l}\text { Total number } \\
\text { Age (years) } \\
\text { Current smokers } \\
\text { Ex-smokers }\end{array}$ & $\begin{array}{l}40(100 \%) \\
48(31 \text { to } 64) \\
11(28 \%) \\
4(10 \%)\end{array}$ & $\begin{array}{l}155(100 \%) \\
51(33 \text { to } 65) \\
15(10 \%) \\
10(7 \%)\end{array}$ \\
\hline $\begin{array}{l}\text { Asthma symptoms* } \\
\text { Chronic bronchitis symptoms } \dagger \\
\text { FEV } 1 \% \text { of predicted) } \ddagger \\
\text { COPD } \$ \\
\text { Bronchial hyperresponsiveness } \neq \ddagger \\
\text { Atopy }{ }^{\star *} \\
\text { Total serum } \lg E>100 \mathrm{kU} / /^{* *}\end{array}$ & $\begin{array}{l}24(60 \%) \\
26(65 \%) \\
99(68 \text { to } 127) \\
2(6 \%) \\
4(18 \%) \\
6(16 \%) \\
10(27 \%)\end{array}$ & $\begin{aligned} & 0(-) \\
& 0(-) \\
& 99(72 \text { to } 125) \\
& 1(1 \%) \\
& 3(3 \%) \\
& 19(15 \%) \\
& 8(6 \%)\end{aligned}$ \\
\hline \multirow{3}{*}{$\begin{array}{l}\text { Current working hours per week in domestic cleaning } \\
\text { Years of employment in domestic cleaning } \\
\text { Ever employed in a non-domestic cleaning job } \\
\text { Ever employed in a non-cleaning job with asthma related } \\
\text { exposurest† } \\
\text { Ever inhaled an important quantity of vapours, gas, or } \\
\text { fumes related to cleaning agents }\end{array}$} & $\begin{array}{l}18(3 \text { to } 50) \\
16(2 \text { to } 53) \\
31(78 \%)\end{array}$ & $\begin{array}{l}16(3 \text { to } 80) \\
17(1 \text { to } 53) \\
54(35 \%)\end{array}$ \\
\hline & $11(28 \%)$ & $55(35 \%)$ \\
\hline & 31 (78\%) & 79 (51\%) \\
\hline
\end{tabular}

Number (\%) or median (minimum to maximum) are given.

*Asthma attack and/or nocturnal attack of shortness of breath in the last year.

tRegular cough and/or regularly bringing up phlegm.

$\neq \mathrm{n}=35$ cases and 126 controls.

$\S \mathrm{FEV}_{1}<80 \%$ of predicted and $\mathrm{FEV}_{1}$ to $\mathrm{FVC}$ ratio $<70 \%$.

- Specific serum lgE to at least one of nine common allergens.

${ }^{* *} n=37$ cases and 126 controls.

††Assessed by using a job exposure matrix with additional expert judgement.

$\ddagger \mp$ Fall of at least $20 \%$ in $\mathrm{FEV}_{1}$ associated with a methacholine dose of $\leqslant 1 \mathrm{mg} ; \mathrm{n}=22$ cases and 95 controls.

mopping the floor (positively) and high frequency of vacuuming (negatively).

Considerable differences were found between the frequency of use of different cleaning products, regarding both the number of users and the frequency of performance (table 3). Products like detergents or liquid multi-use cleaning products were used by almost all women daily, whereas the use of products like undiluted ammonia and hydrochloric acid was much less common. Statistically significant associations were found for ammonia and degreasing sprays or atomisers, which were more frequently used by cases; and for liquid multi-use cleaning products,

Table 2 Associations (unadjusted odds ratios and 95\% confidence intervals) between asthma/chronic bronchitis symptoms, and the frequency of performance of cleaning tasks

\begin{tabular}{|c|c|c|c|c|}
\hline \multirow[b]{2}{*}{ Cleaning task } & \multicolumn{2}{|c|}{ Current performance $(n=195)$} & \multicolumn{2}{|c|}{ OR $(95 \% \mathrm{Cl})$ associated with exposure level +} \\
\hline & Subjects (\%) & $\begin{array}{l}\text { Median freq.* } \\
\text { (times/year) }\end{array}$ & Intermediate & High \\
\hline \multicolumn{5}{|l|}{ General } \\
\hline Dusting & 100 & 364 & $1.2(0.5$ to 2.7$)$ & $1.2(0.5$ to 2.8$)$ \\
\hline Mopping the floor & 99 & 364 & $2.8(1.2$ to 6.8$)$ & $1.1(0.4$ to 3.1$)$ \\
\hline Cleaning windows or mirrors & 99 & 260 & $1.6(0.7$ to 4.0$)$ & $1.9(0.8$ to 4.7$)$ \\
\hline Sweeping & 92 & 416 & $1.1(0.5$ to 2.4$)$ & $0.9(0.4$ to 2.2$)$ \\
\hline Vacuuming & 91 & 180 & $0.6(0.3$ to 1.4$)$ & $0.4(0.2$ to 1.0$)$ \\
\hline Carpet or rug beating & 35 & 52 & & $1.0(0.5$ to 2.2$)$ \\
\hline \multicolumn{5}{|l|}{ Kitchen cleaning } \\
\hline Superficial kitchen cleaning & 100 & 468 & $0.6(0.3$ to 1.4$)$ & $0.6(0.2$ to 1.4$)$ \\
\hline Cleaning the stove or the hob & 99 & 520 & $1.1(0.5$ to 2.7$)$ & $0.5(0.2$ to 1.2$)$ \\
\hline Thorough kitchen cleaning & 99 & 24 & $2.2(1.0$ to 5.3$)$ & $1.1(0.4$ to 2.9$)$ \\
\hline Thorough cleaning of the fridge & 99 & 14 & $0.9(0.4$ to 2.2$)$ & $1.2(0.5$ to 2.8$)$ \\
\hline Washing dishes & 97 & 416 & $2.0(0.8$ to 5.1$)$ & $2.3(1.0$ to 5.3$)$ \\
\hline Cleaning the microwave & 89 & 134 & $1.3(0.5$ to 3.0$)$ & $0.9(0.4$ to 2.1$)$ \\
\hline Cleaning the oven & 85 & 24 & $2.0(0.8$ to 5.0$)$ & $1.9(0.8$ to 4.7$)$ \\
\hline \multicolumn{5}{|l|}{ Bathroom cleaning } \\
\hline Cleaning the bathroom & 100 & 468 & $1.1(0.4$ to 2.6$)$ & $1.1(0.5$ to 2.5$)$ \\
\hline Cleaning the toilet bowl & 99 & 520 & $0.6(0.2$ to 1.4$)$ & $1.1(0.5$ to 2.5$)$ \\
\hline \multicolumn{5}{|l|}{ Laundry } \\
\hline Washing clothes by machine & 100 & 364 & $1.1(0.5$ to 2.6$)$ & $0.6(0.3$ to 1.5$)$ \\
\hline Ironing & 99 & 208 & $0.5(0.2$ to 1.2$)$ & $0.7(0.3$ to 1.6$)$ \\
\hline Washing clothes by hand & 63 & 104 & & $0.9(0.4$ to 1.7$)$ \\
\hline
\end{tabular}

*Median frequency among women reporting current performance of cleaning task.

$\mathrm{tn}=40$ cases and 155 controls. Exposure levels in either two (fixed cut-off level of 12 times/year) or three (tertiles) categories; low exposure level was used as reference category. 
which were more frequently used by controls. Similar ORs were found for undiluted and diluted bleach use; and for undiluted and diluted hydrochloric acid.

Correlations between cleaning tasks and cleaning products were in general weak (data not shown). The highest Spearman's correlation coefficients $\left(r_{s}\right)$ between continuous frequencies were observed for obviously dependent combinations such as "washing clothes by machine" and "detergents" $\left(r_{s}\right.$ 0.93), or "cleaning the bathroom" and "cleaning the toilet bowl" $\left(r_{s} 0.85\right)$. Other correlation coefficients were considerably lower. The only statistically significant negative correlation was between vacuuming and sweeping $\left(r_{s}-0.20\right)$.

When all the relevant exposures were included in a multivariate model the use of bleach, washing dishes, and the use of multi-use cleaning products remained as the most influential exposures (table 4). The use of bleach, either diluted or undiluted, was reported more frequently by cases compared to controls. This resulted in a strong and significant association with a high level of exposure (OR $4.9)$, as well as an exposure-response trend ( $\chi^{2} 8.0$; $\mathrm{p}<0.01)$. Also, frequency of washing dishes was positively associated (ORs 3.2 and $3.1 ; \chi^{2} 4.4$ ) with asthma and chronic bronchitis, whereas using liquid multi-use cleaning products was negatively associated (ORs 0.3 and $0.2 ; \chi^{2} 3.5$ ). Finally, a high risk for asthma and chronic bronchitis was observed for any history of non-domestic cleaning work. Although confidence intervals were wide due to the limited number of cases, the observed associations with bleach and accidental inhalation were more evident for asthma cases than for chronic bronchitis cases. When the analysis was further restricted to the 14 cases with exclusively asthma, ORs remained very similar to those shown for all 24 asthma cases, with exposure to bleach showing ORs of 23 (95\% CI 1.9 to 274) and 14 (95\% CI 1.3 to 153) for intermediate and high levels, respectively.

Airborne exposure levels of both chlorine and ammonia were detectable (that is, $\geqslant 0.1 \mathrm{ppm}$ ) during domestic cleaning work in all 10 measurement sessions. In fig 2 exposure patterns are shown for one of the measurement sessions. In this case increased chlorine levels were related to the use of bleach for bathroom cleaning, and high ammonia levels were related to the use of ammonia for kitchen cleaning. All 10 women used more than one cleaning product during the measurement session, particularly for cleaning the bathroom or the kitchen. Nine of the 10 women used bleach during the measurement session, while the other used two other cleaning products containing chlorine releasing agents. Chlorine was detected during all sessions; the median levels ranged from 0 to $0.4 \mathrm{ppm}$ and peaks ranged up to $1.3 \mathrm{ppm}$. Four of the 10 women used ammonia during the measurement session, while others used cleaning atomisers containing less than $1 \%$ of ammonia according to the manufacturers' information. Airborne ammonia was detectable during all sessions; the median levels ranged from 0.6 to $6.4 \mathrm{ppm}$ while peaks ranged up to more than $50 \mathrm{ppm}$.

\section{DISCUSSION}

This nested case-control study is the first epidemiological investigation specifically designed to identify which occupational exposures are related to the risk of asthma and chronic bronchitis in domestic cleaning workers. The study evaluated exposures to a large range of activities and products, the majority of which were essentially similar for cases and controls. Frequent use of bleach was independently asso-

Table 3 Associations (unadjusted odds ratios and 95\% confidence intervals) between asthma/chronic bronchitis symptoms, and the frequency of use of cleaning products

\begin{tabular}{|c|c|c|c|c|}
\hline \multirow[b]{2}{*}{ Cleaning product } & \multicolumn{2}{|c|}{ Current use $(n=195)$} & \multicolumn{2}{|c|}{ OR $(95 \% \mathrm{CI})$ associated with exposure level† } \\
\hline & Subjects (\%) & $\begin{array}{l}\text { Median freq.* } \\
\text { (times/year) }\end{array}$ & Intermediate & High \\
\hline \multicolumn{5}{|l|}{ Irritant products; used undilutedł } \\
\hline Bleach & 82 & 260 & $1.9(0.7$ to 5.0$)$ & $2.4(1.0$ to 6.1$)$ \\
\hline Ammonia & 16 & 14 & & 3.1 (1.2 to 8.0$)$ \\
\hline Hydrochloric acid & 30 & 6 & & $2.2(0.9$ to 5.3$)$ \\
\hline \multicolumn{5}{|l|}{ Irritant products; used diluted§ } \\
\hline Bleach & 90 & 312 & $1.6(0.7$ to 4.0$)$ & $2.3(0.9$ to 5.4$)$ \\
\hline Ammonia & 56 & 52 & & $0.8(0.4$ to 1.7$)$ \\
\hline Hydrochloric acid & 11 & 12 & & $1.6(0.5$ to 5.5$)$ \\
\hline \multicolumn{5}{|l|}{ Sprays or atomisers } \\
\hline For glass cleaning & 90 & 232 & $0.6(0.2$ to 1.5$)$ & $1.7(0.7$ to 3.7$)$ \\
\hline For degreasing & 84 & 103 & $1.3(0.5$ to 3.3$)$ & $2.6(1.1$ to 6.0$)$ \\
\hline For furniture cleaning & 72 & 116 & $1.6(0.7$ to 3.9$)$ & $1.7(0.7$ to 4.0$)$ \\
\hline For floor mopping & 47 & 104 & & 0.7 (0.3 to 1.4$)$ \\
\hline Insecticides & 42 & 34 & & $1.3(0.6$ to 2.8$)$ \\
\hline For oven cleaning & 39 & 20 & & $1.2(0.5$ to 2.5$)$ \\
\hline For air refreshing & 30 & 84 & & $1.6(0.8$ to 3.4$)$ \\
\hline For ironing & 27 & 52 & & $0.6(0.3$ to 1.5$)$ \\
\hline For cleaning carpets, rugs, or curtains & 15 & 6 & & $2.0(0.6$ to 7.0$)$ \\
\hline \multicolumn{5}{|l|}{ Other products } \\
\hline Detergents & 100 & 364 & $1.4(0.6$ to 3.0$)$ & $0.6(0.2$ to 1.5$)$ \\
\hline Liquid multi-use cleaning products & 95 & 364 & $0.6(0.3$ to 1.3$)$ & $0.4(0.2$ to 1.0$)$ \\
\hline Decalcifiers & 70 & 52 & $0.9(0.4$ to 2.1$)$ & $1.2(0.5$ to 2.7$)$ \\
\hline Stain removers & 35 & 52 & & $0.9(0.4$ to 2.0$)$ \\
\hline Polishes, waxes & 34 & 52 & & $0.9(0.4$ to 2.0$)$ \\
\hline Drain cleansing agents & 23 & 3 & & $0.0(-)$ \\
\hline Dry cleaning foams & 19 & 4 & & $2.0(0.6$ to 7.0$)$ \\
\hline \multicolumn{5}{|c|}{$\begin{array}{l}{ }^{*} M e d i a n \text { frequency among women reporting current use of cleaning product. } \\
t n=40 \text { cases and } 155 \text { controls. Exposure levels in either two (fixed cut-off level of } 12 \text { times/year) or three (tertiles) categories; low exposure level was used as } \\
\text { reference category. } \\
\text { †Product used directly as commercially available. } \\
\S \text { Product diluted in a bucket of water before being used. }\end{array}$} \\
\hline
\end{tabular}




\begin{tabular}{|c|c|c|c|c|c|c|c|}
\hline & $\begin{array}{l}\text { Controls } \\
\left(n=152^{*}\right)\end{array}$ & $\begin{array}{l}\text { All cases } \\
(\mathrm{n}=40)\end{array}$ & OR $(95 \% \mathrm{Cl})$ & $\begin{array}{l}\text { Asthma } \\
(n=24)\end{array}$ & OR $(95 \% \mathrm{Cl})$ & $\begin{array}{l}\text { Chronic bronchitis } \\
\text { without asthma } \\
\text { (n=16) }\end{array}$ & OR $(95 \% \mathrm{Cl})$ \\
\hline \multicolumn{8}{|c|}{ Bleach (both undiluted and diluted) } \\
\hline$<364$ times/year & 56 & 8 & 1.0 & 3 & 1.0 & 5 & 1.0 \\
\hline 364-640 times/year & 53 & 11 & $3.3(0.9$ to 11$)$ & 9 & $10(1.7$ to 60$)$ & 2 & $0.9(0.1$ to 6.5$)$ \\
\hline$\geqslant 640$ times/year & 43 & 21 & $4.9(1.5$ to 15$)$ & 12 & $12(2.3$ to 67$)$ & 9 & $2.6(0.6$ to 12$)$ \\
\hline \multicolumn{8}{|c|}{ Use of liquid multi-use cleaning products } \\
\hline$<266$ times/year & 50 & 20 & 1.0 & 13 & 1.0 & 7 & 1.0 \\
\hline $266-480$ times/year & 51 & 12 & $0.3(0.1$ to 0.8$)$ & 6 & $0.2(0.0$ to 0.7$)$ & 6 & $0.3(0.1$ to 1.6$)$ \\
\hline$\geqslant 480$ times/year & 51 & 8 & $0.2(0.1$ to 0.6$)$ & 5 & $0.1(0.0$ to 0.5$)$ & 3 & $0.2(0.0$ to 1.3$)$ \\
\hline \multicolumn{8}{|l|}{ Washing dishes } \\
\hline$<376$ times/year & 64 & 10 & 1.0 & 8 & 1.0 & 2 & 1.0 \\
\hline 376-520 times/year & 37 & 12 & $3.2(1.0$ to 10$)$ & 6 & $2.0(0.5$ to 8.9$)$ & 6 & 7.5 (1.0 to 53$)$ \\
\hline$\geqslant 520$ times $/$ year & 51 & 18 & $3.1(1.1$ to 8.9$)$ & 10 & $3.8(1.0$ to 14$)$ & 8 & $6.5(0.9$ to 47$)$ \\
\hline \multicolumn{8}{|c|}{$\begin{array}{l}\text { Inhalation of an important quantity of vapours, } \\
\text { gas, or fumes related to cleaning agents }\end{array}$} \\
\hline Never & 73 & 9 & 1.0 & 5 & 1.0 & 4 & 1.0 \\
\hline Ever & 79 & 31 & $2.3(0.9$ to 6.1$)$ & 19 & $3.8(1.0$ to 14$)$ & 12 & $0.9(0.2$ to 4.3$)$ \\
\hline \multicolumn{8}{|c|}{ Employment in non-domestic cleaning } \\
\hline Never & 101 & 9 & 1.0 & 5 & 1.0 & 4 & 1.0 \\
\hline Ever & 51 & 31 & 8.5 (3.2 to 23$)$ & 19 & $12(3.2$ to 46$)$ & 12 & $7.9(1.6$ to 39$)$ \\
\hline \multicolumn{8}{|l|}{ Smoking } \\
\hline Never & 127 & 25 & 1.0 & 19 & 1.0 & 6 & 1.0 \\
\hline Currently & 15 & 11 & 4.1 (1.1 to 15$)$ & 2 & $0.5(0.1$ to 3.9$)$ & 9 & 22 (3.6 to 137) \\
\hline Formerly & 10 & 4 & $5.3(1.1$ to 25$)$ & 3 & 5.5 (0.9 to 33$)$ & 1 & $8.9(0.5$ to 173$)$ \\
\hline
\end{tabular}

Multiple logistic regression analyses adjusted for all listed variables and age tertile.

*Three controls had missing values for one or more of the exposure variables and were not included in this multivariate model.

ciated with respiratory symptoms, predominantly of asthma. Current or former employment in non-domestic cleaning work, washing dishes, and antecedents of an accidental inhalation of large amounts of vapours, gas, or fumes from cleaning products were also associated with an increased risk. The findings of our study suggest that the main determinants of increased risk of asthma symptoms among women employed in domestic cleaning are chronic exposures to inhaled irritants.

The use of bleach, which was extremely common in our study population, was consistently associated with respiratory symptoms and particularly with symptoms of asthma. The active component of household bleaches is the chlorine releasing agent sodium hypochlorite in amounts that are equivalent to $3-10 \%$ available chlorine, a strong airway irritant gas. ${ }^{16}$ Manufacturers add typically around $1 \%$ of sodium hydroxide to bleach as a product stabiliser in order to keep the $\mathrm{pH}$ in the alkaline region and hence to inhibit chlorine release. ${ }^{17}$ Nevertheless, our exposure measurements showed readily detectable amounts of free chlorine during normal bleach use without mixing with other cleaning agents, including situations where bleach was applied after dilution in water. Washing the dishes more than daily was also associated with asthma and chronic bronchitis symptoms. Although specific information on applied products for dishwashing was not obtained, most likely this referred predominantly to manually doing the dishes using water with dishwashing liquid. Interestingly, mixing bleach with dishwashing liquid was not uncommon in this population, being reported as common practice by $25 \%$ of the cases and $15 \%$ of the controls. A chemical reaction of hypochlorite from the bleach with either ammonium salts from the dishwashing liquid, or with organic matter from the dishes may lead to the release of chloramines. ${ }^{18}$ We also found indications that the use of other irritant cleaning agents such as degreasing sprays or atomisers, hydrochloric acid, and ammonia might be related to asthma and chronic bronchitis symptoms, although these exposures did not remain in the final model. The active component of degreasing sprays is sodium hydroxide (up to $5 \%$ ), a mucous membrane irritant.
Although sodium hydroxide is not volatile, the application through spraying may facilitate respiratory exposure to liquid aerosols containing this strong alkaline irritant. Concentrated hydrochloric acid (around 20\%) is sold as a cleaning product in Spain, known as Aguafuerte or Salfuman(t). Household ammonia is commercially available as a $4-10 \%$ solution of aqueous ammonia, which is very volatile. Our measurements showed that common household application of ammonia results in relevant airborne exposure levels, with 5-second time weighted average peaks of more than $35 \mathrm{ppm}$, the 15minute average short term occupational exposure limit in many countries. Thus, the agents associated with respiratory symptoms in our study are of irritant nature and their chronic use in occupational domestic cleaning may have involved harmful inhalatory exposures likely to result in increased prevalence of asthma and possibly chronic bronchitis.

Within our population of domestic cleaning women, current or former employment in non-domestic cleaning was strongly and independently associated with symptoms of asthma and chronic bronchitis. This finding is consistent with our previous cross-sectional analysis where, despite no association between exclusively non-domestic cleaning and respiratory symptoms, those reporting simultaneous employment in domestic and non-domestic cleaning were at an increased risk, ${ }^{6}$ suggesting the presence of an interaction. In the present case-control study both cases and controls were domestic cleaners and, consistent with the latter interaction, those reporting non-domestic cleaning activities were also at an increased risk although the mechanism responsible for this interaction remains unclear. In addition, the response rate in the present study was slightly higher in cases reporting non-domestic cleaning, thus providing an additional explanation for an increased risk in this group.

We defined case status based on the presence of symptoms of asthma and chronic bronchitis since our population based survey had shown that employment in domestic cleaning was equally associated with both asthma and chronic bronchitis symptoms. ${ }^{6}$ The presence of respiratory symptoms usually shows a large temporal variability ${ }^{7}$ and we adopted a 


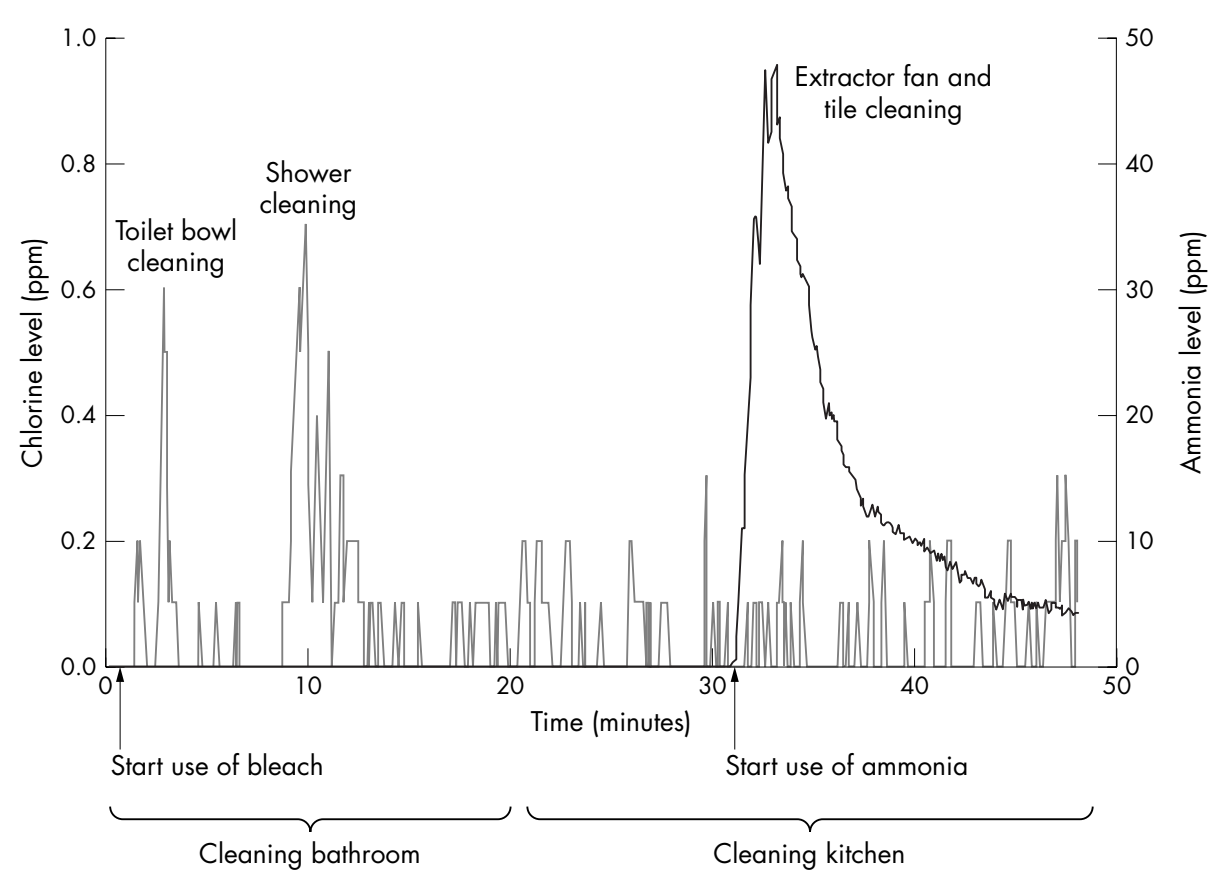

Figure 2 Pattern of personal airborne chlorine and ammonia exposure (5-second time weighted average) during domestic cleaning work. The graph corresponds to a 55 year old woman with a history of 26 years in domestic cleaning work, currently employed in one home for cleaning eight hours weekly. Chlorine and ammonia concentrations in ppm are indicated by the grey line and the black line, respectively. Recommended occupational exposure limits (15-minute time weighted average) amount to $0.5 \mathrm{ppm}$ and $35 \mathrm{ppm}$ for chlorine and ammonia, respectively. ${ }^{15}$

restrictive definition of cases and controls as those reporting or denying, respectively, symptoms both at the time of the population based survey and at the time of the case-control interview. This approach is conservative because the time period between the two interviews was relatively short (from June 2000 to April 2002), and we assumed that change in symptom status between both interviews may have been importantly biased by measurement error in self-reported symptoms. ${ }^{19}$ The validity of our case definition is supported by the large difference in the rates of BHR ( $18 \%$ versus $3 \%$ ) and increased total IgE (27\% versus $6 \%)$ between cases and controls. The observed prevalence of BHR is consistent with data reported in a population based study of asthma in young adults in Spain with 11\% of asymptomatic subjects and 22\% of asthmatics showing BHR. ${ }^{20} \mathrm{FEV}_{1}$ levels were, on average, very similar for cases and controls, although the number of cases with a reduction in $\mathrm{FEV}_{1}$ qualifying for COPD was present in $6 \%$ of cases and $1 \%$ of controls, a difference that was consistent with the higher prevalence of a lifetime smoking history among cases (38\%) compared to controls $(17 \%)$. Atopy was similar in cases and controls, strongly suggesting that increased prevalence of respiratory symptoms in cleaners was not mediated by an allergic mechanism. This is consistent with a previous observation that atopy in cleaning workers with asthma was less common than in office workers with asthma. ${ }^{21}$ In addition, we have previously reported that specific sensitisation to allergens potentially related to domestic cleaning activities like detergent enzymes was not observed in cleaning workers. ${ }^{5}$ For this reason, we did not test specific sensitisation to detergent enzymes in our study. Although our sample size precludes any strong inference about separating the effects of occupational exposure for asthma and chronic bronchitis, it is of interest that the observed associations with irritants were particularly strong for women with asthma symptoms and much less for those with chronic bronchitis symptoms. The latter is also reassuring in that the associations between respiratory symptoms and cleaning exposures were not due to residual confounding by smoking, which is more strongly related to chronic bronchitis than to asthma.

Our study was restricted to prevalent cases and consequently the results referring to work related symptoms make it impossible to disentangle whether the investigated exposures were responsible for new-onset disease or produced the aggravation of a pre-existing disease. ${ }^{22}$ The epidemiological evidence relating occupational exposure to irritants and respiratory symptoms is scarce and is mostly related to occupational asthma. New-onset asthma has been suggested to result from recurrent or chronic occupational exposures to moderate levels of airway irritants. ${ }^{23-25}$ The latter has been described after repeated exposures to among others chlorine, $^{26}$ ammonia and alkaline agents, ${ }^{25}$ and other not specified cleaning agents. ${ }^{23}$ Occupational asthma due to chronic exposure to chloramines has been described in a case series of swimming pool workers. ${ }^{18}$ The exposures alluded to above are similar to the exposures associated with symptoms in our study, and therefore one plausible explanation is that the type of effects associated to occupational domestic cleaning correspond to those described in the context of so-called "low-dose reactive airways dysfunction syndrome" (low-dose RADS). In addition, a large number of women in our study reported antecedents of accidental inhalation of high levels of irritants, an exposure that has been associated with the development of RADS; persistent asthma with a sudden onset. ${ }^{27}$ The accidents reported in our study were predominantly related to inadequate mixtures of bleach with either hydrochloric acid or ammonia, leading to a rapid release of important amounts of free chlorine and chloramines, respectively. ${ }^{28}{ }^{29}$ Cases with RADS have been related to a variety of respiratory irritants, including chlorine, ammonia, and hydrochloric acid. ${ }^{30} 31$ Both case reports and surveillance studies show consistent evidence for RADS due to cleaning agents, although the epidemiological and retrospective nature of our study makes it impossible to assess the presence of RADS cases in this workforce based population. Finally, the association between chronic exposure to irritants 
Main messages

- Domestic cleaning women are exposed to a wide variety of cleaning agents, resulting in relevant respiratory exposures to airway irritants.

- Asthma symptoms in domestic cleaning women are related to frequent use of bleach, and possibly also to other irritant cleaning agents.

- Inhalation accidents related to cleaning agents are common among domestic cleaning women.

and chronic bronchitis may be also a partial explanation for our results since it has been recognised that regular exposure to airway irritants in the workplace may lead to mucus hypersecretion and to chronic productive cough in the absence of asthma, often referred to as chemical or industrial bronchitis. $^{32} 33$

There are a number of limitations in our study that should be considered. First, results were based on self-reported frequencies of current specific cleaning exposures involving the possibility of misclassification. If present, this was probably non-differential and could have resulted in a bias towards the null. Although the possibility of reporting bias cannot be discarded, the fact that for most reported exposures the frequency was similar in cases and controls was against this possibility. Furthermore, it is not unlikely that the recall of inhalation accidents related to cleaning products and subsequent symptoms was more likely for cases than for controls. This may partly explain the observed positive association for reported accidents. Selection bias might be related to the fact that more cases than controls had abandoned the use of highly irritant cleaning agents for respiratory health reasons, as suggested in our study for undiluted hydrochloric acid (results not given). Consequently, this has probably led to an underestimation of the risks associated with these exposures. Second, due to the restrictive case definition and to a not negligible nonresponse, despite having identified 117 potential cases, we ended up with 40 in this analysis. This small sample size led to a limited statistical power for the analyses and some potentially relevant associations may have remained undetected. Finally, certain statistical associations observed in our study were not anticipated and are not easy to interpret. The finding of a negative association between symptoms and the use of liquid multi-use cleaning products has no obvious explanation. However, considering the large number of products involved in domestic cleaning, competing exposures for a given task is likely to occur. In other words, if cases are more likely to use bleach or other irritants as a consequence of a true effect they may be less likely to use other competing products, which in their turn will exhibit negative associations with case status. This possibility is supported by correlations between multi-use and ammonia that were negative among cases and positive among controls (results not given).

The findings reported in the present study may have significant implications for public health. Domestic cleaning is in many countries one of the largest occupational categories among women, implying relevant attributable risks for respiratory disease. As far as we know this is the first study reporting respiratory morbidity in women employed in domestic cleaning. Several factors may have contributed to the lack of studies in this workforce, mainly a tendency to neglect occupational health problems in women and the usual unregulated nature of this type of work. Although we focused on respiratory morbidity, other health
Policy implications

- Avoiding or safer use of irritant cleaning products would reduce respiratory morbidity among domestic cleaning women.

- The use of bleach and other irritant cleaning products is widespread, both in the workplace and at home, justifying further study to evaluate potential public health impact.

- Domestic cleaning is one of most common female occupations in many countries, but to date occupational health problems have hardly been recognised. More attention to occupational hazards in the informal sector is needed.

problems like musculoskeletal morbidity, dermatitis, or psychosocial disorders may also be relevant in this population. ${ }^{34}$ Cleaning products are also used in a large number of other occupational settings. Results from a recent surveillance study in the United States showed that $78 \%$ of work related asthma cases due to cleaning products occur in noncleaning occupations such as nurses or clerical workers. ${ }^{35}$ In addition, a large proportion of the general population is potentially at risk when cleaning their own home. Another US surveillance study showed that exposure to household cleaning agents was among the most frequent causes of nonwork related hospital admission for chemical related respiratory disease. ${ }^{36}$ The use of bleach, which was found to be associated with respiratory symptoms, is widespread in Spanish homes as a conventional cleaning product. Unpublished results of the follow up of the ECRHS ${ }^{8}$ showed that the use of household bleach varied widely across European countries. Although its use was most common in Spain, in several other European countries more than half of the homemakers reported using bleach at least once a week. Respiratory health effects of non-professional home cleaning exposures require further study.

In conclusion, asthma symptoms in domestic cleaning women are related to the regular use of bleach and possibly other irritant products, pointing towards an irritant induced effect mechanism. Further research is needed to investigate the public health impact of the use of irritant cleaning products in cleaning workers, in other occupations, and in the household.

\section{ACKNOWLEDGEMENTS}

The study was supported by grant CICYT/FEDER 2FD97-2071 from the Spanish Ministry of Science and Technology; by grant 01/3058 from the Carlos III Health Institute, Spanish Ministry of Health and Consumption; and by the Spanish Network of Epidemiology and Public Health (RCESP). We thank Beatriz Palomino, Natalia Molina, Dave Macfarlane, and Laura Bouso (IMIM, Barcelona) for their contribution to the recruitment of the study population, and data collection and management; Emma Gavarre from the Primary Health Care Centre Sant Ildefons for kindly providing facilities; Xavier Guardino from the National Institute of Occupational Safety and Hygiene for assistance with exposure measurement methodology; and Hans Kromhout (University of Utrecht, Netherlands), Juha Pekkanen (National Public Health Institute, Kuopio, Finland), Paul Cullinan and Anthony Newman-Taylor (National Heart \& Lung Institute, London, UK) for their helpful comments on the report.

\section{Authors' affiliations}

M Medina-Ramón, J P Zock, M Kogevinas, J Sunyer, Y Torralba,

A Borrell, J M Antó, Respiratory and Environmental Health Research Unit, Institut Municipal d'Investigació Mèdica, (IMIM), Barcelona, Spain 
F Burgos, Servei de Pneumologia i Al-lèrgia Respiratòria, Dept de Medicina, Hospital Clínic, Universitat de Barcelona, Barcelona, Spain

Competing interests: none declared

\section{REFERENCES}

$1 \mathrm{Ng} \mathrm{TP}$, Hong CY, Goh LG, et al. Risks of asthma associated with occupations in a community-based case-control study. Am J Ind Med 1994;25:709-18.

2 Kogevinas M, Antó JM, Sunyer J, et al. A population based study on occupational asthma in Europe and other industrialised countries. Lancet 1999;353:1750-4.

3 Karialainen A, Kurppa K, Martikainen R, et al. Work is related to a substantial portion of adult-onset asthma incidence in the Finnish population. Am J Respir Crit Care Med 2001;164:565-8.

4 Arif AA, Delclos GL, Whitehead LW, et al. Occupational exposures associated with work-related asthma and work-related wheezing among U.S. workers. Am J Ind Med 2003;44:368-76.

5 Zock JP, Kogevinas M, Sunyer J, et al. Asthma risk, cleaning activities and use of specific cleaning products in Spanish indoor cleaners. Scand J Work Environ Health 2001;27:76-81.

6 Medina-Ramón M, Zock JP, Kogevinas $M$, et al. Asthma symptoms in women employed in domestic cleaning: a community-based study. Thorax 2003;58:950-4

7 Strachan DP, Butland BK, Anderson HR. Incidence and prognosis of asthma and wheezing illness from early childhood to age 33 in a national British cohort. BMJ 1996;312:1195-9.

8 The European Community Respiratory Health Survey II Steering Committee The European Community Respiratory Health Survey II. Eur Respir J 2002;20:1071-9.

9 Kennedy SM, Le Moual N, Choudat D, et al. Development of an asthma specific job exposure matrix and its application in the epidemiological study of genetics and environment in asthma (EGEA). Occup Environ Med 2000;57:635-41.

10 Burney PGJ, Luczynska D, Chinn S, et al. The European Community Respiratory Health Survey. Eur Respir J 1994;7:954-60.

11 American Thoracic Society. Standardization of spirometry: 1994 update. Am J Respir Crit Care Med 1995; 152:1107-36.

12 Roca J, Burgos F, Sunyer J, et al. References values for forced spirometry. Eur Respir J 1998;11:1354-62.

13 The COPD Guidelines Group of the Standards of Care Committee of the BTS BTS guidelines for the management of chronic obstructive pulmonary disease. Thorax 1997;52(suppl 5):S1-28.

14 Chinn S, Burney $P$, Jarvis D, et al. Variation in bronchial responsiveness in the European Community Respiratory Health Survey (ECRHS). Eur Respir $J$ 1997; 10:2495-501.

15 NIOSH. NIOSH pocket guide to chemical hazards. NIOSH Publication No. 2001-145. Washington, DC: DHHS (NIOSH), 2001.

16 Das R, Blanc PD. Chlorine gas and the lung: a review. Toxicol Ind Health 1993;9:439-55.
17 Racioppi F, Daskaleros PA, Besbelli N, et al. Household bleaches based on sodium hypochlorite: review of acute toxicology and poison control center experience. Food Chem Toxicol 1994;32:845-61.

18 Thickett KM, McCoach JS, Gerber JM, et al. Occupational asthma caused by chloramines in indoor swimming-pool air. Eur Respir J 2002;19:827-32.

19 Chinn S, Jarvis D, Burney P, et al. Increase in diagnosed asthma but not in symptoms in the European Community Respiratory Health Survey. Thorax 2004;59:646-51.

20 Sunyer J, Munoz A. Concentrations of methacholine for bronchial responsiveness according to symptoms, smoking and immunoglobulin $E$ in a population-based study in Spain. Spanish Group of the European Asthma Study. Am J Respir Crit Care Med 1996;153:1273-9.

21 Zock JP, Kogevinas M, Sunyer J, et al. Asthma characteristics in cleaning workers, workers in other risk jobs, and office workers. Eur Respir J 2002;20:679-85

22 Becklake MR, Malo JL, Chan-Yeung M. Epidemiological approaches in occupational asthma. In: Bernstein IL, Chan-Yeung M, Malo JL, et al. Asthma in the workplace, 2nd edn. New York: Marcel Dekker, 1999:27-65.

23 Kipen H, Blume R, Hutt D. Asthma experience in an occupational environmental medicine clinic. Low dose reactive airways dysfunction syndrome. J Occup Med 1994;36:1133-7.

24 Brooks SM, Hammad Y, Richards I, et al. The spectrum of irritant-induced asthma. Sudden and not-so-sudden onset and the role of allergy. Chest 1998;113:42-9.

25 Quirce S, Gala G, Pérez-Camo I, et al. Irritant-induced asthma: clinical and functional aspects. J Asthma 2000;37:267-74.

26 Chan-Yeung M, Lam S, Kennedy SM, et al. Persistent asthma after repeated exposure to high concentrations of gases in pulpmills. Am J Respir Crit Care Med 1994; 149:1676-80.

27 Brooks SM, Weiss MA, Bernstein IL. Reactive airways dysfunction syndrome (RADS). Persistent asthma syndrome after high level irritant exposures. Chest 1985;88:376-84.

28 Centers for Disease Control. Chlorine gas toxicity from mixture of bleach with other cleaning products, California. JAMA 1991;266:2529-34

29 Pascuzzi TA, Storrow AB. Mass casualties from acute inhalation of chloramine gas. Mil Med 1998;163:102-4.

30 Gautrin D, Bernstein IL, Brooks S. Reactive airways dysfunction syndrome, or irritant-induced asthma. In: Bernstein IL, Chan-Yeung M, Malo JL, et al. Asthma in the workplace, 2nd edn. New York: Marcel Dekker, 1999:565-93.

31 Alberts WM, do Pico GA. Reactive airways dysfunction syndrome. Chest 1996;109:1618-26.

32 Balmes JR. Occupational airways diseases from chronic low-level exposures to irritants. Clin Chest Med 2002;23:727-35.

33 Hendrick DJ. Occupation and chronic obstructive pulmonary disease (COPD). Thorax 1996;51:947-55.

34 Krüger D, Louhevaara V, Nielsen J, et al. Risk assessment and preventive strategies in cleaning work, Werkstattberichte Wissenschaft + Technik, Wb 13. Hamburg, 1997.

35 Rosenman KD, Reilly MJ, Schill DP, et al. Cleaning products and work-related asthma. J Occup Environ Med 2003;45:556-63.

36 Reilly MJ, Rosenman KD. Use of hospital discharge data for surveillance of chemical-related respiratory disease. Arch Environ Health 1995;50:26-30. 